\title{
"NOSSO IRMÃO MAIS VELHO": FLORESTAN FERNANDES, LEITOR DE MARIÁTEGUI*
}

Deni Alfaro Rubbo

Doutorando em Sociologia na USP; bolsista Capes. São Paulo, SP. Brasil.

E-mail:<deni_out27@uol.com.br>

http://dx.doi.org/10.1590/ 0102-6445079-105/99

Para Silvia Beatriz Adoue

As modas vã̃o e vêm.

O pensamento criador, dentro da ciência ou fora dela, fica. (Florestan Fernandes, A sociologia no Brasil, 1976, p. 141)

\section{No labirinto da América Latina: o encontro entre Florestan e Mariátegui}

Cravados vinte anos de sua morte, um dos mais renomados sociólogos do Brasil, Florestan Fernandes, continua a desafiar gerações de pesquisadores dos mais diferentes campos das ciências humanas, além de proporcionar reflexões aos militantes sociais e políticos comprometidos com a transformação social do país. Não há dúvida de que sua vasta obra estabeleceu a sociologia como ciência no Brasil (Arruda, 1995), atravessando o campo da sociologia profissional,

Agradeço às funcionárias e estagiárias da biblioteca de Florestan Fernandes, em particular a Livia de Lima Reis, como também a Vera Lucia Coscia, cuja ajuda foi fundamental para decifrar letras/frases anotadas por Florestan, nem sempre legíveis. 
pública, militante e crítica (Braga, Garcia e Silva, 2009), mas também suscitando discussões em outras disciplinas, da ciência política à antropologia, da história à educação.

Mesmo sendo uma obra amplamente estudada em seus distintos aspectos, resta muito trabalho para descobrir as múltiplas dimensões e influências que marcam a trajetória intelectual de Florestan ${ }^{1}$. É de se ressaltar o "ecletismo bem temperado" (Cohn, 1987) de Florestan de modo que a capacidade de se surpreender com sua obra é permanente, uma vez que a alta envergadura teórica e erudição de seus escritos, referências diretas ou indiretas com as quais o autor trabalhava não eram poucas. Basta visitar, por exemplo, sua biblioteca particular situada na Universidade Federal de São Carlos (UFSCar), que conta com um acervo de mais de 13 mil livros do autor. Certamente um pesquisador interessado pela obra de Florestan e pela sociologia brasileira ficará surpreso com a quantidade de anotações, rascunhos, grifos, notas, cartas e 80 fichamentos que o sociólogo fazia durante seu trabalho intelectual. Esse material poderia suscitar pistas interessantíssimas e abrir uma agenda de estudos dos componentes da trajetória e do pensamento de Florestan.

$\mathrm{O}$ interesse de Florestan pelos dilemas do continente latino-americano, assim como pela produção política e sociológica do marxismo no Novo Continente também tem sido um tema promissor, ainda que pouco explorado entre os especialistas (Cf. Costa, 2010). O encontro entre Florestan e a América Latina ocorrerá efetivamente após o decreto de sua aposentadoria compulsória da Universidade de São Paulo (USP), dada pela ditadura civil-militar através do Ato Institucional $\mathrm{n}^{\circ} 5$ no final de 1968, que obrigou o sociólogo paulista a aceitar o convite para lecionar na Universidade de Toronto (Canadá), para onde se mudou no ano seguinte.

1 Para mais informações sobre a trajetória de Florestan, ver, entre outros, Garcia (2002), Sereza (2005), Martins (1998) e Cerqueira (2004). 
A partir da década de 1970, duas dimensões se constituem com total intensidade na produção e na trajetória do sociólogo: se aprofundar nos estudos do marxismo, através da leitura dos clássicos (Marx, Engels, Lênin), e em seus estudos sobre América Latina². Desse modo, aprofundar-se-á sua reflexão sobre o Brasil e sobre sua condição de sociólogo socialista.

É durante esse período de intensa radicalização política que, provavelmente, Florestan descobre a obra de José Carlos Mariátegui (1894-1930), elo pioneiro na fusão entre marxismo e América Latina ${ }^{3}$. Como afirmou o sociólogo mexicano Adolfo Sánchez Vásquez (1998, p. 54), o peruano foi um dos pensadores mais originais que procuraram "produzir um marxismo que corresponde à realidade latino-americana”. Todavia, é claro, Florestan não estava sozinho nessa descoberta. Autores latino-americanos de sua geração, como Orlando Fals Borda, Pablo González Casanova, Oscar Terán, Rodolfo Stavenhagen, Gerárd Pierre-Charles, José Nun, Aníbal Quijano, entre outros, separadamente e de modo independente, foram responsáveis pela consolidação das ciências sociais em seus respectivos países e estavam imbuídos das mesmas metas, do ponto de vista investigativo, que Mariátegui. Florestan Fernandes (1975, p. xv), mais tarde, comentaria esse curioso parentesco: "As metas que se propõe [Mariátegui] explicitamente são as mesmas que se iriam impor, reiteradamente, daí em diante, às várias gerações de cientistas sociais

2 O interesse de Florestan pela produção bibliográfica de países da América Latina se reconfirma, por exemplo, nas 88 páginas de fichamentos, divididos em dois blocos menores presentes na Biblioteca Comunitária/Decore/Fundo Florestan Fernandes 02044667 (Gaveta 03). Nesses blocos, há uma vasta bibliografia histórica, política e sociológica, toda em inglês, de países como Cuba, Guatemala, Venezuela, Bolívia, Colômbia, Haiti, Chile, Argentina, Republicana Dominicana, México, Peru e Brasil.

3 Doravante JCM em alguns momentos. Dentre as dezenas de livros e artigos que buscaram introduzir a vida e a obra de Mariátegui, mencionaremos apenas alguns deles: Melis (1999), Rouillon (1975), Illan (1974), Quijano (1980), Paris (1981), Fernández (2010), Scorsim (2006), Rodrigues (2010). 
na América Latina". Nesse sentido, todos alavancavam temáticas semelhantes sobre o caráter especial da periferia no sistema capitalista mundial e a especificidade da construção da sociedade de classes como o tema da dependência, do imperialismo e do caráter da burguesia. Esse boom de pensamento radical latino-americano no final da década de 1960 e início da década de 1970 situava-se igualmente em um contexto de radicalização dos processos políticos pela qual passavam os países da América Latina ${ }^{4}$. Não apenas JCM figurava entre as referências latino-americanas importantes de Florestan Fernandes, mas também o cubano José Martí, o argentino Sérgio Bagú, o brasileiro Caio Prado Júnior, entre outros.

De todo modo, Florestan será um dos responsáveis pela divulgação da obra do teórico peruano no Brasil. Mais do que isso, seria justamente o sociólogo brasileiro "o primeiro grande impulsionador da obra mariateguiana no Brasil, de facto" (Pericás, 2010, p. 345). Foi por incentivo de Florestan que, em 82 1975, a editora Alfa Ômega conseguiu publicar, pela primeira vez no país, os Sete ensaios de interpretação da realidade peruana (Mariátegui, 1975), livro publicado originalmente em 1928, apontado como o mais influente estudo histórico de uma nação da América do Sul. Com mais de 47 anos de atraso da publicação original, a edição brasileira contaria ainda com um pequeno prólogo de Florestan reafirmando a importância intelectual do livro por suas temáticas inovadoras. A descrição que o sociólogo brasileiro faz no prólogo destaca não apenas o pioneirismo de uma obra pela qualidade "lúcida e notável", mas também pelas temáticas trazidas à luz do método marxista e pela linguagem que combinou profundidade e acessibilidade.

Mariátegui não se afirma apenas como pioneiro. Ele promove as primeiras análises concretas, de uma perspectiva marxista, de vários temas cruciais: a formação

4 Conforme entrevista com Diogo Valença de Azevedo Costa. 
do capitalismo na Espanha, a irradiação do capitalismo da Europa para a América Latina, as transformações da dominação imperialista sob o impacto do aparecimento e fortalecimento da grande corporação ou da presença norteamericana, e, sobretudo, as relações entre base econômica e as estruturas sociais e de poder da sociedade peruana, nas várias fases do período colonial e do período nacional. Em uma linguagem extremamente densa mas muito clara, ele sempre resume o essencial, partindo com frequência dos resultados das melhores investigações já realizadas, cujo aproveitamento e análise crítica ele nunca esconde aos leitores (Fernandes, 1975, p. xviii).

Anos depois, como coordenador da Coleção Grandes Cientistas Sociais, Florestan convidou dois professores de história da Universidade Estadual Paulista (Unesp campus Assis), Manoel Lelo Belloto e Ana Maria Martinez Corrêa, para organizar a coletânea José Carlos Mariátegui (Belloto e Corrêa, 1982). Seria a primeira publicação no Brasil de artigos de Mariátegui reunidos em livro, além de uma introdução e um levantamento bibliográfico sobre sua vida e pensamento político. Resultado de cursos de pós-graduação ministrados pelos autores sobre América Latina, o livro foi lançado em 1982, tempo de muita dificuldade para dar cabo ao empreendimento solicitado por Florestan. Afinal, compor uma bibliografia sobre um autor peruano declaradamente socialista ou, até mesmo, a própria escolha de investigar a formação social do continente latino-americano era vista com desconfiança pelos signatários da ditadura civil-militar, além da dificuldade de conseguir bibliografia adequada ${ }^{5}$. Não custa lembrar que esse reconhecimento de pioneiro das ideias de Mariátegui no Brasil já tinha sido notado pelo estudioso peruano Ricardo Luna Vegas (1985, p. 86), autor do qual Florestan tinha alguns livros em sua biblioteca.

5 Informação dada por Ana Maria Martinez Corrêa em entrevista. 
Para além de divulgar Mariátegui no país, é possível flagrar Florestan utilizando-se da obra mariateguiana em seus textos, entrevistas e intervenções públicas. Uma das declarações que o reforçam está num livro-entrevista, publicado em 1978 sob o título A condição de sociólogo. Curiosamente, o sociólogo marxista, em um primeiro momento, destaca como Mariátegui foi pródigo por realizar um balanço crítico, integral e decisivo do movimento modernista no Peru (especialmente no ensaio sobre a literatura dos Sete ensaios). Em suas palavras,

[...] aí [em Mariátegui] temos, de fato, uma interpretação densa, crítica e negadora do Peru. O Peru do passado, o Peru do presente, desembocando em uma concepção totalizadora e integradora da transformação do Peru através de uma revolução socialista (Fernandes, 1978, p. 36).

Ainda segundo Florestan, os modernistas brasileiros fica84 ram aquém do papel crítico que lhes caberia da sociedade brasileira. Eles teriam aberto concessões justamente para aquilo que deveriam fazer oposição. Afinal, o "modernismo é a negação da consciência burguesa, o anti da consciência conservadora" (p. 35; grifo do autor). Por essas razões, a obra mariateguiana com sua densidade crítica deveria servir como parâmetro de análise do que ocorreu no modernismo no Brasil.

Eu gosto de usar o paralelo com Mariátegui porque ele é didático e nos mostra, de uma vez e para sempre, o que o movimento modernista "deveria ser", mas não foi.

Compare-se os Sete ensaios com a produção dos nossos modernistas (Fernandes, 1978, p. 33) ${ }^{6}$.

6 O sociólogo e literato Antonio Candido (1996, p. 5) comenta e critica a postura negativa do amigo sociólogo brasileiro em relação ao movimento modernista e a comparação injusta com Mariátegui: "Florestan sempre deu importância capital à fundação da Universidade e da nossa Faculdade. Mas talvez seja meio injusto quando a compara com o movimento modernista. São coisas diferentes, com funções 
Não por acaso, nas breves anotações à margem que fez do último dos Sete ensaios, presente em sua biblioteca particular, Florestan insinua que se deve comparar o processo de modernismo peruano com o do Brasil, especialmente através da revista modernista Colónida (fundada em 1916), que "equivale ao modernismo aqui [no Brasil]" (grifo nosso) ${ }^{7}$.

Em outro momento, Florestan ressalta ainda que rapidamente a importância de Mariátegui como exemplo de "investigação científica engajada” na América Latina, juntamente com Caio Prado Júnior e Sérgio Bagú. O trabalho em questão seria o afamado ensaio "Reflexões sobre as 'Revoluções Interrompidas' (uma rotação de perspectivas)", de 1981, composto no livro Poder e contrapoder na América Latina. O objetivo do texto é questionar até que ponto a transformação capitalista nos países latino-americanos não rompeu completamente "com formas coloniais de exploração do trabalho e nos quais as classes se tornaram burguesas através e atrás do desenvolvimento do capitalismo" (Fernandes, 1981, p. 72). Tanto Mariátegui como Caio Prado e Sergio Bagú, segundo Florestan, antecipariam conclusões da esquerda revolucionária dos anos 1970 ao desvendarem o caráter especial do capitalismo em países de origem colonial. Finalmente, no início do

históricas diferentes, e não podem ser comparadas como ele faz. Ele fala de modernismo como se fosse uma empresa de cunho político que não correspondeu ao que se esperava; e é sintomático que lembre Mariátegui em detrimento dos nossos escritores daquela vanguarda. Ora, Mariátegui era um político, um militante de esquerda, um líder de alto porte, que era também escritor. O seu alvo era outro. Creio que Florestan minimiza a carga específica de fantasia e liberdade criadora que são fundamentais no domínio da arte e da literatura, e que devem constituir a pedra de toque para avaliar movimentos como o modernista, em cujos participantes o papel ideológico e a ação prática são por assim dizer subprodutos".

7 Como se sabe, Mariátegui ajudou a fundar, juntamente com Abraham Valdelomar, Percy Gibson e José Maria Eguren, entre outros, a revista em que publicou poemas. Sua participação na juventude do grupo não impediu que, posteriormente, tivesse um distanciamento crítico diante do "movimento", que "constituía um sentimento ególatra, individualista, vagamente iconoclasta, imprecisamente inovador" (Mariátegui, 1969, p. 282). Para uma análise sobre o assunto, ver Reyes (1996). 
opúsculo divulgado durante campanha eleitoral à Câmara dos Deputados, em julho de 1990, intitulado "Em defesa do socialismo", o teórico político e jornalista peruano volta a ser mencionado. Eis as palavras iniciais de Florestan (1995, p. 201): "o título deste escrito lembra Mariátegui que reuniu vários ensaios em um famoso livro: Em defesa do marxismo. As oscilações históricas provocam essas recorrências". A provocação contida na última frase sugere justamente atualizar o marxismo em meio à hecatombe da burocracia do assim chamado "socialismo real". Como veremos adiante, quatro anos depois, isto é, um ano antes da morte de Florestan, é com essa mesma intenção que ele vai redigir um artigo exclusivamente sobre a atualidade do marxismo através do projeto teórico-político de Mariátegui.

\section{Entre livros, poeiras e leituras: a biblioteca de Florestan Fernandes}

86 Na biblioteca particular de Florestan é possível encontrar livros de Mariátegui, lidos e anotados que parecem ter-lhe suscitado grande interesse. Antes de avançarmos no que Florestan tinha especificamente disponível, no que destacou e no que anotou nas obras do marxista peruano, cabe registrar a importância desse universo particular que era sua biblioteca e, por extensão, do ofício de seu trabalho intelectual - isto é, livros, leituras, grifos, anotações.

Eram mais de 13 mil títulos, sem contar aqueles que eventualmente foram extraviados, emprestados (e não devolvidos) ou simplesmente vendidos. Essas são apenas algumas das razões pelas quais não devemos pretender que a análise da biblioteca de Florestan determina o que ele tivesse lido. De qualquer forma, até o final da vida, Florestan tinha na memória praticamente todos os livros e revistas que possuía. Em depoimento, Heloisa Fernandes (1998, p. 49), filha de Florestan, afiança: 
Seus livros eram sua fortuna, mas não fetiches a serem limpos, ilustrados, encadernados. Tal como só as crianças sabem fazer com seus tesouros, seus livros eram valores de uso, lidos e relidos por um leitor ativo, atento, exigente, que anota, escreve, rabisca, grifa, a tal ponto que, muitas vezes, restam, afinal, dois textos: o do próprio autor e o do seu leitor!

Quais eram, então, os livros de (e sobre) Mariátegui que Florestan possuía em sua biblioteca? Conforme o quadro abaixo, são ao todo doze livros disponíveis: quatro de Mariátegui (Siete ensayos..., Historia de la crisis mundial, Defensa del marxismo, Ideología y política) oriundos da coleção "obras completas", conhecidas como edições populares; oito sobre Mariátegui, dos quais quatro do peruano Ricardo Luna Vegas (dois deles com dedicatória do autor a Florestan), um livro organizado pelo marxista argentino José Aricó e um exemplar do primeiro número da revista peruana Anuario Mariateguiano, dirigida por Antonio Melis e Alberto Tauro. Há, ainda, dois exemplares de um livro que o sociólogo Aníbal Quijano organizou e prefaciou pela editora mexicana Tierra Firme, ambos também com dedicatória. Além disso, Florestan também tinha em seu acervo boletins (como o Boletín Informativo del Centenário de José Carlos Mariátegui), cartazes, pôsteres sobre JCM com fotos, especialmente de comemorações de seu centenário, em $1994^{8}$.

Para entender a importância da presença dos volumes listados no Quadro 1, na biblioteca de Florestan, cabe um rápido parêntese sobre as origens das "Obras completas" de JCM. Em 1956, os filhos de Mariátegui (especialmente o primogênito Sandro), como maiores responsáveis pela empreitada, decidem publicar a primeira edição "popular" da obra do pai, que teve tiragem de 50 mil exemplares,

8 UFSCar - Biblioteca Comunitária/Decore/Fundo Florestan Fernandes $4111 / 6631 / 6632 / 6633 / 7507$. 


\section{Quadro 1}

\section{Livros de/sobre Mariátegui na biblioteca particular de Florestan Fernandes}

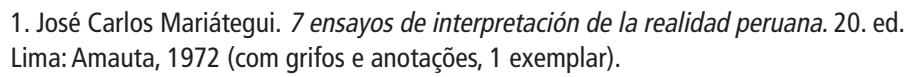

1. José Carlos Mariátegui. 7 ensayos de interpretación de la realidad peruana. 20. ed. Lima: Amauta, 1972 (com grifos e anotações, 1 exemplar).

2. José Carlos Mariátegui. Ideología y política. 10. ed. Lima: Amauta, 1979 (com grifos e anotações em alguns artigos, 1 exemplar).

3. José Carlos Mariátegui. Historia de la crisis mundial. 6. ed. Lima: Amauta, 1979 (com grifos e anotações no primeiro capítulo, 1 exemplar).

4. José Carlos Mariátegui. Defensa del marxismo: polémica revolucionaria. 9. ed. Lima: Amauta, 1980 (com grifos e poucas anotações, 1 exemplar).

5. Ricardo Luna Vegas. José Carlos Mariátegui. 1894-1930: ensayo biografico. Lima: Editorial Horizonte, 1986 (sem grifos nem anotações, 1 exemplar).

6. Ricardo Luna Vegas. Mariátegui y el Peru de ayer, de hoy y de mañana. Lima: Ediciones Rincon Rojo, 1981 (sem grifos nem anotações, 1 exemplar).

7. Ricardo Luna Vegas. Introducción a Mariátegui. Lima: Causachun, 1975 (sem grifos nem anotações, 1 exemplar).

8. Ricardo Luna Vegas. Mariátegui, Haya de la Torre y la verdad histórica. Lima: Retama, 1978 (com grifos e anotações, 1 exemplar).

9. José Aricó (org.). Mariátegui y las orígenes del marxismo latino-americano. México: Pasado y Presente, 1978 (sem grifos nem anotações).

10. VV. AA. Revista Anuario Mariateguiano, n. 1, Lima, Amauta, 1989 (sem grifos nem anotações).

11. Anibal Quijano (org.). José Carlos Mariátegui: textos básicos. México: Tierra Firme, 1991 (grifos e anotações somente no prólogo, 2 exemplares).

Fonte: UFSCar - Biblioteca Comunitária/Decore/Fundo Florestan Fernandes.

vendidos a preços acessíveis em várias províncias do Peru. Com o sucesso de venda, inúmeras edições de bolso foram impressas. Inicialmente, a coleção dotada de vinte volumes, abarcava apenas os textos do retorno da viagem à Europa, em 1923, até a morte, em 1930, ou seja, um conjunto de produção de sete anos (Pericás, 2011, p. 119). Entre 1987 e 1994, foram acrescidos mais oito tomos dos "Escritos de juventude", além da correspondência, de dois tomos, pre- 
parada pelo italiano Antonio Melis (1994). Em comparação com a bibliografia disponível atualmente, os livros que Florestan possuía - ao menos os que hoje se encontram em sua biblioteca - representam uma pequena parcela da obra de Mariátegui, mas, no contexto e época em que foram adquiridos, consistiam nos principais livros então disponíveis. Há, portanto, razões suficientes para identificarmos um enorme interesse do sociólogo marxista em adquirir parte substantiva dos livros que estavam ao seu alcance.

Não custa lembrar que Mariátegui publicou apenas dois livros em vida: La escena contemporánea (1925) e o Siete ensayos (1928). Presente na biblioteca de Florestan, este último foi grifado e anotado abundantemente, do começo ao fim, especialmente nos três primeiros capítulos. Aliás, esse livro é o com a edição mais antiga entre todos os outros, de 1972. Provavelmente foi o primeiro livro que Florestan leu de Mariátegui. É verdade que o pensador peruano tinha alguns poucos livros em preparação, que foram lançados postumamente. Um deles, Defensa del marxismo, originalmente publicado em 1956 (embora tenha circulado uma edição incompleta pirata - no Chile em 1933), teve poucos grifos e apenas uma pequena anotação do sociólogo brasileiro. Assim, "todo o resto de sua obra é resultado de um difícil trabalho de pesquisa e compilação de dezenas e dezenas de textos (muitos deles, jornalísticos)" (Pericás, 2011, p. 119), que discutiam temas tão diversos como crítica literária, artigos políticos, contos, poemas, peças de teatro, um "romance-reportagem", assim como textos sobre educação, artistas e escritores, a questão indígena e agrária, assuntos mundiais, entre outros ${ }^{9}$ É o caso do livro Historia de la crisis mundial, um ciclo de conferências

\footnotetext{
9 Para Mazzeo (2013, p. 33), sem desmerecer a importância da iniciativa de organização de seus escritos por temas, a empreitada provavelmente não tenha sido a melhor forma de captar "o sentido histórico e unitário" da obra mariateguiana. Uma tentativa - embora incompleta - de catalogar os textos de Mariátegui cronologicamente pode ser consultada em Rouillon (1963).
} 
que Mariátegui fez na Universidade Popular González Prada, durante o biênio 1923-1924, que reúne versões completas e parciais, estas últimas encontradas nos diários da época. Dele, Florestan grifou apenas o texto da primeira conferência intitulado "A crise mundial e o proletariado peruano". Ideología y política também é um livro com artigos esparsos. Escritos políticos e sindicais, polêmicas em periódicos, teses políticas, ideologia de linhas editoriais de periódicos e revistas eram o que caracterizaria a tônica dos artigos e documentos do volume. Florestan grifou vários trechos e algumas anotações à margem de oito deles: "El problema de las razas en la América Latina" (apenas a primeira parte), "Punto de vista antiimperialista", "Antecedentes y desarollo de la acción clasista", "Hacia la Confederación General de Trabajadores del Peru", "La Central Sindical del Proletariado Peruano", "La Confederación General de Trabajadores del Perú", "Estatutos y regulamentos de la 'Oficina de Auto-Educación Obrera'” e 90 "Principios Programáticos del Partido Socialista”.

\section{Nas margens: impressões de um leitor atento}

Na maior parte dos textos mencionados, Florestan faz anotações à margem, bem pontuais, apenas destacando alguma afirmação. De qualquer forma, não se trata aqui de examinar à exaustão todo esse conjunto, mas de captar algumas ideias-chave que chamaram a atenção de Florestan. Embora seja possível flagrar uma afinidade entre as ideias de Mariátegui e Florestan, isso não significa que o sociólogo brasileiro realize uma leitura passiva e ingênua. As margens também servem a diversas correções (e advertências) de textos lidos por Florestan. Ou seja, existe uma relação de estranhamento com algumas colocações do autor peruano. Por exemplo, nos Sete ensaios - o caso mais paradigmático das correções -, ele questiona em diversos momentos algumas formulações: se Mariátegui afirma que o problema do índio deve ser explicado numa chave econômica social e não pelo mecanismo administrativo, 
jurídico ou eclesiástico. Florestan, sem deixar de concordar com o argumento, escreve que o problema também toca em outras fibras, já que a "política" e a "estru. [estrutura] de poder e dominação estiveram tb. [também] presentes!" - curiosamente um argumento tipicamente weberiano! Trata-se de um apontamento de feição mais metodológica, mas não deixa de ser curioso que, no ensaio sobre a questão indígena, não há uma única nota de Florestan exclusivamente sobre a questão, já que esse era um tema conhecido pelo autor que havia publicado A organização social dos Tupinambá e A função social da guerra na sociedade Tupinambá - certamente uma de suas contribuições mais originais. Talvez porque o indígena andino e o indígena brasileiro, especialmente o Tupinambá, fossem completamente distintos. Se Mariátegui afirma que "a conquista foi um ato político", Florestan questiona "e não econômico?". Se Mariátegui nomeia as tradições comunitárias do campesinato indígena peruano como "comunismo inca", Florestan faz a seguinte indagação: "e o tipo de estratificação existente?". Exemplos não faltam nessa direção.

Talvez uma das questões mais prementes na leitura de Florestan e na interpretação que fazia das particularidades do capitalismo periférico no circuito mundial tenha sido a relação intrínseca entre estruturas coloniais e capitalismo. Nem sempre Mariátegui construiu essa relação de maneira satisfatória, a bem da verdade. Às vezes, transparece certa ideia de sociedades duais em se tratando dos modos de produção, mas de maneira residual, já que, na maior parte dos momentos, podemos ver uma colocação contrária. Por exemplo, quando Mariátegui (2010 [1928], p. 70) trata do problema da terra, afiança que "as raízes do feudalismo estão intactas. Sua subsistência é responsável, por exemplo, pelo atraso de nosso desenvolvimento capitalista. [...] Sobre uma economia semifeudal não podem prosperar nem funcionar instituições democráticas feudais". Florestan notifica à margem dessas duas afirmações uma observação: "única limitação: 
focaliza o interno sem o externo como concomitante". Para Florestan, não é que a aristocracia latifundiária da Colônia tinha conservado de maneira intacta seus "direitos feudais" sobre a terra, apesar do advento da República. Em realidade, ela conservou as estruturas coloniais de dominação e poder econômico e político. Em outras notas, o sociólogo segue na mesma direção: "em vez de feudal = preservação de estruturas coloniais", "a regra = a burguesia capitalista que perpetuam a[s] estruturas coloniais!”. Haveria também uma diferença sutil, mas importante entre os termos "colonial" e "neocolonial". País de raízes tipicamente coloniais, com advento da República, mas sem romper com as estruturas de dependência, o Peru expressa, na verdade, uma economia neocolonial. Por isso, Florestan "corrige" a afirmação mariateguiana segundo a qual "a economia do Peru é uma economia colonial" - ele anota, "seria melhor - neocolonial".

De qualquer maneira, antes de serem falhas incorrigí92 veis, esses seriam os traços do trabalho de um leitor atento e exigente sobre um autor cuja obra considerava "lúcida" e "notável”. Florestan (1975, p. xviii) explica essas lacunas ou insuficiências no prefácio ao Sete ensaios:

[...] se perfilhou uma terminologia que hoje é considerada inadequada - e portanto infeliz - isso só ocorre em poucos passos, como no tratamento analítico que dá à assimilação da organização colonial ao modelo feudal e à discussão da tenacidade dos resíduos feudais ${ }^{10}$.

\footnotetext{
${ }^{10}$ Sobre as insuficiências categoriais de Mariátegui, Florestan assinala outro ponto não menos importante. No mesmo prefácio, ele afirma que o intelectual peruano teve contato e aprofundamento com o marxismo através de seus anseios políticos revolucionários (e não o inverso) por meio de uma elaboração indireta, "quanto ao significado do materialismo histórico como método para conhecer a realidade e, nesse caráter, servir de base à consciência social crítica e à ação política revolucionária" (e não direta, "no plano da organização e da direção dos movimentos de massa para fins políticos especificamente revolucionários"). Daí, "se explicam, segundo pensamos, aparentes incoerências ou ambiguidades puramente 'teóricas' ou 'doutrinárias' de Mariátegui” (Fernandes, 1975, p. xvii).
} 
Em geral, Florestan enxerga na obra de Mariátegui um pensador que estava correto no plano analítico e explicativo de suas observações e conclusões. Não por acidente, o texto que mais chamou a atenção do sociólogo brasileiro, do começo ao fim, foi "Punto de vista antiimperialista", tese apresentada à Primeira Conferência Comunista Latino-Americana (Buenos Aires, junho de 1929). Ao que tudo indica, Florestan apreciou positivamente o documento redigido pelo marxista peruano. Isso se confirma no final do texto, em que Florestan escreve o seguinte comentário: "Provavelmente $=0$ escrito mais pertinente e criador de M. [Mariátegui] = suas conclusões só se tornariam empiricamente evidentes para os imperialistas com o relt. [relatório] Rockeffer [Rockfeller]; e globais para esquerda rev. [revolucionária] na década de 60 - um antecipador". Em vários trechos, ele escreve palavras à margem como "certo", "correto", "bravo!", "boa!", mostrando-se entusiasmado e sintonizado com as ideias desenvolvidas, especialmente com a caracterização política, social e econômica que Mariátegui endereça às burguesias latino-americanas.

Quais seriam essas características? Mariátegui afirma que as burguesias nacionais não têm nenhuma inclinação para admitir a necessidade de lutar pela "segunda independência”. Inexiste um programa de autonomia nacional, um nacionalismo revolucionário. Na Indo-América, "a aristocracia e a burguesia crioulas não se sentem solidárias com o povo pelos laços de uma história e de uma cultura comuns" (Mariátegui, 1988b [1929], p. 88). Sublinhando essa frase, Florestan escreve a seguinte nota ao lado: "bravo! (por que se cometeram tantos erros depois desses escritos?)". Certamente, ele se refere aos partidos comunistas da América Latina que adotaram como estratégia política a aliança com a burguesia "nacional" na crença de uma "etapa democrático-nacional e antifeudal" da 
revolução no continente ${ }^{11}$. Na conclusão do texto em que Mariátegui (1988b [1929], p. 95) ${ }^{12}$ afirma sua postura anti-imperialista e revolucionária - "somos anti-imperialistas porque somos marxistas, porque somos revolucionários, porque opomos ao capitalismo o socialismo como sistema antagônico" -, Florestan destaca o excerto em um tom de lamentação e escreve: "deveria ter sido a base pol. [política] dos PCs na Al. [América Latina]". Essa conduta política catastrófica dos partidos comunistas na América Latina é realçada novamente por Florestan à margem de uma longa nota de rodapé nos Sete ensaios: "não existe 'burguesia progressista'.... = já antes de 1928 = portanto, o erro da estratégia dos $\mathrm{PCs}$ na $\mathrm{Al}=$ não é resultado da falta de percepção intel. [intelectual] da real. [realidade]!"”.

Fica claro que a hipótese de Mariátegui acerca de uma burguesia impotente no subcontinente agradou o sociólogo marxista. Ainda, no documento "El problema de las razas 94 en la America Latina”, texto publicado originalmente em 1929, Florestan destaca os seguintes trechos: "uma burguesia medíocre, débil, formada no privilégio" e "a maior falta que se pode imputar à classe dominante da república é não ter sabido acelerar, com uma inteligência mais liberal, mais burguesa, mais capitalista de sua missão, o processo de transformação da economia colonial em economia capitalista" (Mariátegui (1988a [1929], p. 32). Em prognóstico, Mariátegui (1988b [1929], p. 89) afirma que sempre haverá colaboração das burguesias do subcontinente enquanto a política imperialista conseguir manipular os sentimentos e as formalidades da soberania nacional dos Estados, "enquanto não se vir obrigada a recorrer à intervenção armada e à

${ }^{11}$ É verdade que Mariátegui em determinado momento insinua que a burguesia argentina, onde seria "numerosa e rica", poderia ser uma exceção à regra, ou seja, "progressista", ainda que isso fosse improvável. Florestan adverte para qualquer resquício de esperança desse tipo: "enganou-se!".

${ }^{12}$ Todas as citações referentes a Mariátegui (1988 [1929]) são tradução nossa. 
ocupação militar". Trecho esse sublinhado pelo sociólogo brasileiro como "correto", já que era exatamente isso que estava ocorrendo nos países latino-americanos na década de 1970. Florestan faz o seguinte comentário à margem: “que pena! (nem mesmo pelas razões capitalistas)". Ou seja, as burguesias jamais iriam aderir a tal projeto, mesmo por um programa capitalista autônomo. Essa avaliação política imperialista no subcontinente estaria totalmente ausente na teorização aprista, segundo Mariátegui, e também pelos epígonos "stalinistas", como completa Florestan.

Evidentemente, é difícil não traçar um paralelo com as hipóteses maturadas especialmente em A revolução burguesa no Brasil (Fernandes, 2005 [1975]) ${ }^{13}$. Nesse sentido, algumas pistas podem ser aferidas ${ }^{14}$. Na primeira pequena brochura biográfica sobre o Amauta no Brasil, traduzida por Carlos Nelson Coutinho, o autor argentino Hector Alimonda (1983, p. 86) afirma, embora não explique em profundidade, que em A revolução... Florestan leva em conta sugestões de Mariátegui. De fato, o Sete ensaios será mencionado no final da bibliografia do livro. Mas, afinal, quais seriam os elementos possíveis que compõem essa relação? Na mesma direção, em um ensaio dedicado à categoria de revolução

\footnotetext{
${ }^{13}$ Para uma análise de alguns conceitos deste livro, ver Ricupero (2008) e Arruda (1996).

${ }^{14}$ Na verdade, há uma pista alternativa. Durante os anos 1990, em uma coletânea de artigos intitulada Florestan ou o sentido da coisas, o historiador Carlos Guilherme Mota (1998, p. 18) recorda de uma temporada curta em Austin (Texas), EUA, em 1976, que passara com o amigo Florestan. Na ocasião, um colóquio interdisciplinar foi realizado sobre o recente livro lançado pelo sociólogo brasileiro com vários convidados ilustres, entre os quais Emília Viotti da Costa, Richard Graham, Silviano Santiago e David Jackson. Um dos palestrantes daquele seminário chamaria a atenção do historiador brasileiro: o "saudoso" Alejandro Losada, crítico literário peruano, "que na ocasião elaborou interessante paralelo entre Mariátegui e Florestan” (Mota, 1998, p. 18). Sabe-se que, um ano depois, Losada publicou um ensaio sobre a literatura latino-americana a partir do ponto de vista marxista (em especial inspirados nos trabalhos do jovem Lukács e de Antonio Candido), na extinta revista Contexto, da qual Florestan fazia parte da comissão editorial (ver Losada, 1977). Embora não tenhamos conseguido acesso ao conteúdo da palestra de Losada, mencionado por Mota, é possível fazer constar como um dos episódios entre Florestan e Mariátegui.
} 
de Florestan, José Paulo Netto (1987, p. 301) assinala que o sociólogo brasileiro "incorpora a lição de Mariátegui" de revolução no que toca à particularidade que a definição do termo requer, já que o Brasil se situa na órbita da periferia do capitalismo mundial. Netto ressalta uma afirmação de Mariátegui publicada no editorial da revista Amauta, "Aniversario y balance”, em 1928: “A própria ideia de Revolução, nesta América de pequenas revoluções, presta-se a muitos equívocos. Temos de reivindicá-la rigorosa e intransigentemente". Acrescenta ainda: "Esta reivindicação traveja o universo intelectual de Florestan e permeia a sua recuperação marxiana e marxista" (Netto, 1987, p. 301). No entanto, talvez a melhor a pista seja do próprio Florestan Fernandes (1975, p. XVIII) sobre os Sete ensaios:

[...] no plano analítico e explicativo suas observações e conclusões mostram-se corretas e encontram quase total corroboração nas investigações recentes. Que nos sirvam de exemplo suas breves mas luminosas análises do processo de revolução burguesa no Peru, com suas vicissitudes, atrofiamento e consequências negativas para a revolução nacional peruana.

Observações e conclusões que remetem principalmente à oscilação histórica negadora das burguesias peruana e brasileira no estabelecimento de liberdades democráticas em seus respectivos países. E sua impotência para conjugar uma revolução nacional (unificação da nação e emancipação da dominação imperialista) com uma revolução democrática (abolição de todos os resíduos de escravidão, liquidação de todas as formas pré-capitalistas de exploração, distribuição de terra do campesinato). Porém, o diagnóstico dos Sete ensaios não ia acompanhado por uma alternativa: se analisava o que era o Peru, mas não havia uma proposta do que deveria ser. A proposta política aparece, um ano depois (1929, na 
Primeira Conferência Comunista Latino-Americana), de maneira clara e precisa, no texto já analisado "Punto de vista antiimperialista", além de desenvolver com maior profundidade a caracterização de uma burguesia frágil e conservadora. É provável que Florestan não conhecesse esse texto antes da publicação em 1975 de seu A revolução burguesa no Brasil, pois a edição que possuía de Ideología y política era a de 1979. Arriscamos a dizer que caso tivesse lido antes, certamente seria um texto amplamente trabalhado no seu livro de 1975. A revolução burguesa... estaria, do ponto de vista da análise macrossociológica e da forma ensaio, mais próxima do Sete ensaios. E, do ponto de vista do conteúdo político, mais afinada ao "Punto de vista antiimperialista". Ou seja: nem Florestan, nem Mariátegui apostavam, nas condições específicas do capitalismo selvagem na periferia do capitalismo mundial, em uma "revolução dentro da ordem”.

\section{"Todo meu sangue em minhas ideias": o significado atual de Mariátegui}

Resultado de um convite dos editores do Anuario Mariateguiano, revista peruana que tinha como objetivo divulgar os trabalhos sobre JCM - e no ano de 1994, estava dedicando um número especial ao centenário do nascimento do pensador peruano -, Florestan escreveu um ensaio intitulado "Significado atual de José Carlos Mariátegui”"15. Trata-se de um artigo relativamente

\footnotetext{
${ }^{15}$ Esse texto também foi compilado como um dos capítulos do seu último livro, $A$ contestação necessária: retratos intelectuais de inconformistas e revolucionários (Fernandes, 2015 [1995]). Interessante notar que na introdução da parte que o artigo está incluído, Florestan faz a seguinte observação das motivações que o fizeram a escrever sobre o marxista peruano: "recorri a uma simulação fecunda: o que faria José Carlos Mariátegui nesta era de incerteza para o socialismo? Ele sucumbiria à moda e à propaganda demolidora do marxismo nas nações capitalistas hegemônicas? Minha suposição é que Mariátegui possuía uma personalidade incorruptível e indomável. Baseio-me no fato de que ele foi pioneiro em duas frentes: na pugna com conservadores, que encaravam o marxismo como ilusão; e na crítica a companheiros que não avançavam com sua fibra e perspicácia na interpretação da situação histórica peruana e latino-americana. Não cedeu o passo. Levou seus combates às últimas consequências, oferecendo a todos as mesmas respostas de quem sabe o que e por
} 
curto, mas denso, instigante, com um turbilhão de ideias, conexões inesperadas. De certo modo, mais do que um artigo científico, o texto é, sobretudo, uma intervenção política intempestiva e refinada. Os inúmeros adjetivos ao longo do texto não escondem a simpatia e admiração do sociólogo brasileiro em relação ao autor dos Sete ensaios: "espírito criativo", "intelectual polimórfico", "autêntico revolucionário", "intelectual marxista por excelência da América Latina", "produtor de conhecimento e homem de ação", "inteligência sociológica" etc. O objetivo do texto não é apresentar a trajetória e a obra intelectual e política de Mariátegui e seus possíveis desdobramentos. Sem diminuir a importância desses estudos - ele cita como exemplo o livro organizado por José Aricó, na verdade, existiria uma intenção política bastante clara: através da figura de Mariátegui e de seu projeto teórico-político, Florestan testaria a (pseudo) validade das ideias de "fim das ideologias" e dos slogans "desaparecimento do socialismo" e "morte do comunismo", que 98 estavam em voga no contexto de redação do texto.

A primeira tentativa de desmistificar a ideia de que “o socialismo está morto" - e talvez a principal do texto - é defender um Mariátegui crítico implacável das ideologias do progresso. Nesse contexto, Florestan Fernandes (1994, p. 81) destaca o que considera uma qualidade do pensador peruano: "Sua convicção era clara: os progressos do capitalismo redundam em aumento geométrico da barbárie. Essa realidade sempre foi subestimada de uma perspectiva eurocêntrica”. De fato, a defesa da ideia de desenvolvimento do capitalismo e da ideologia do progresso como motor inexorável da história se fez presente tanto no espectro político conservador quanto no "revolucionário"16. A perspectiva eurocêntrica marxista,

que faz. Em consequência, sua figura admirável eleva-se como exemplo em um universo de oportunismo e capitulação" (Fernandes, 2015, p. 41).

${ }_{16}$ Nesse sentido, existe um paralelismo impressionante entre Mariátegui e as ideias de Walter Benjamin, que, na década de 1930, exigia que o materialismo histórico aniquilasse a ideia de progresso. Em Passagens, o pensador alemão assevera: 
por exemplo, se limitava a transplantar mecanicamente para a América Latina os modelos de desenvolvimento socioeconômico que explicam a evolução histórica da Europa ao longo do século XIX, como se a periferia do mundo capitalista fosse uma mera repetição do espaço central. Essa crítica da perspectiva eurocêntrica, ou das "ilusões eurocêntricas" especialmente dentro do marxismo - e Marx ${ }^{17}$ e Mariátegui como figuras resistentes a ela - serão enfatizadas inúmeras vezes ao longo de "Significado actual de José Carlos Mariátegui" (Fernandes, 1994). É também um acerto de contas de Florestan com a ideia de progresso. Não deixa de ser curioso, para não dizer empobrecedor, que justamente a ênfase de um pensamento marxista descolonizador, que Florestan sublinha com tanto vigor, tenha sido abandonada pelos assim chamados estudos pós-coloniais da América Latina (com exceção de Enrique Dussel e Aníbal Quijano) que enxergam o marxismo como uma teoria exclusivamente ocidental e europeia.

Por outro lado, Florestan formulou questões que supostamente Mariátegui poderia ter feito em relação às peculiaridades do capitalismo na década de 1990. Como nesse trecho, por exemplo: "nos dias que correm, Mariátegui - ao contrário de tantos anarquistas, socialistas e comunistas - encontraria dentro de si a indagação fundamental: como representar e explicar a totalidade histórica ao capitalismo monopolista automatizado?" (Fernandes, 1994, p. 82). Afinal, como afirmou Roland Forgues (1993, p. 77), a mundialização da economia, a universalização da dominação e a interações dos povos e das culturas constituía já na década de 1920 um dos principais axiomas do pensamento de Mariátegui.

\footnotetext{
"Pode-se considerar um dos objetivos metodológicos deste trabalho demonstrar um materialismo histórico que aniquilou em si a ideia de progresso. Precisamente aqui o materialismo histórico tem todos os motivos para se diferenciar rigorosamente dos hábitos de pensamento burgueses. Seu conceito fundamental não é o progresso, e sim a atualização" (Benjamin, 2007, p. 502).

17 Sobre Marx e a ruptura com o eurocentrismo, ver Anderson (2015); Bianchi (2010); Tible (2013), especialmente o primeiro capítulo deste último.
} 
Não há dúvida de que essa também era uma das preocupações candentes de Florestan nos últimos anos de sua vida: deslindar as contradições do capitalismo monopolista da era atual vulgarmente conhecida como "globalização". É provável que o sociólogo marxista coloque Mariátegui nessa família de intérpretes sobre a dinâmica do capitalismo de seu tempo, já que este esteve impulsionado em vista de um projeto de "investigação macro-histórica de modelo marxista", na qual procurou estudar a formação e o desenvolvimento do capitalismo no Peru. Desse modo, teria tido a capacidade de "observar, representar e explicar processos históricos de longa duração e de uma proposta revolucionária concomitante, que vincula dialeticamente passado, presente e futuro" (Fernandes, 1994, p. 85; grifos nossos). Assim, pelo esforço de interpretação histórica livre de etnocentrismos (ou muito próximo disso), Mariátegui lido por Florestan foi aquele que "se propôs a enriquecer o marxismo fora 100 e acima dos eixos eurocêntricos”, priorizando uma visão totalizante da realidade social peruana.

Florestan ressalta outra qualidade de Mariátegui que está organicamente relacionada com as demais características apresentadas acima: "a discreta defesa intransigente do marxismo”. Uma formulação bastante curiosa, um pouco enigmática, mas que está longe de ser contraditória. A própria diferença que marca os debates entre Mariátegui e a figura de Haya de la Torre, assim como "os entrechoques entre a teoria e prática marxista na URSS (e como eles se equacionavam externamente, graças à arquitetura e à relação entre meios e fins da Internacional Comunista)" (Fernandes, 1994, p. 83) - temas amplamente estudados e repletos de controvérsias entre os "mariateguistas" - podem ser entendido a partir da interpretação que Mariátegui tinha do marxismo. Não é coincidência que o marxista peruano tenha suscitado as mais espúrias desconfianças e incompreensões tanto do marxismo "oficial”, europeísta, ossificado, quanto 
do assim chamado "excepcionalismo indo-americano" (Löwy, 1999), o que o levou por muito tempo ao ostracismo político perante a esquerda peruana.

Essa experiência dramática, que se deu com outras figuras de projeção equivalente, conferiu maior profundidade à sua ótica marxista. Eu a encaro como o fator primordial da grandeza de sua perspectiva histórica e do conteúdo cerrado adquirido por sua visão do marxismo, em todos os seus desdobramentos (Fernandes, 1994, pp. 83-84).

Em outro trecho lê-se: "Patenteia-se, pois, o quanto Mariátegui transcendeu à órbita do marxismo triunfante do seu tempo e o quanto ele compartilha conosco na necessidade de ir mais longe ou perecer" (Fernandes, 1994, p. 82). Em síntese, o Mariátegui de Florestan possui um marxismo crítico e independente não apenas por sua contribuição criativa à reflexão da formação social peruana, mas também como uma das tentativas mais significativas do campo marxista de romper com o evolucionismo, a ideologia do progresso linear e o eurocentrismo. Florestan Fernandes (1994, p. 87), no final do artigo, assevera: "as proposições de Mariátegui marchariam como antes, de acordo com a redução de Engels: socialismo ou barbárie? São proposições que não foram varridas pela tempestade". Além de Engels, Rosa Luxemburgo também conservou a afirmação "Socialismo ou barbárie?", aliás, com mais intensidade, rompendo com a concepção da história reificada como progresso inexorável. Dessas lições, resulta que o pensamento de JCM, com todas as limitações que teve, segundo Florestan Fernandes (1994, p. 87), "ainda se ergue como um farol, que ilumina o horizonte intelectual e político dos que querem conferir aos latino-americanos a opção pelo marxismo".

Por todos os elementos trazidos neste artigo, Florestan Fernandes não foi apenas um divulgador da obra mariate- 
guiana no Brasil. É verdade que somente o fato de recepcionar uma figura de proa da história do marxismo latino-americano já seria de grande relevância. "Mariátegui é o nosso “irmão mais velho", disse certa vez Florestan. "Irmão" não só em termos biográficos (há inegáveis semelhanças, a origem social humilde, o autodidatismo, por exemplo), como também por uma evidente afinidade analítica e política com passagens de estranhamento. Fato é que, diante da vastidão da obra de Florestan, Mariátegui figura como uma referência teórica marxista decisiva na fase "militante-política" do autor, como foram Marx e Lênin, e como expressão importante de como estudar um país da periferia do sistema do capitalismo monopolista através do método marxista. Ele não constitui $a$ matriz teórica das reflexões do sociólogo brasileiro, mas não deixa de ser uma referência indispensável, que tratou com profundidade, esforço e lucidez dos dramas sociais e históricos da América Latina. De todo modo, Mari-

102 átegui lido por Florestan faz parte da árvore genealógica do marxismo crítico e engajado na América Latina - e muito provavelmente a semente principal dessa família que teve bons frutos durante as décadas de 1960 e 1970. Isso fica evidente não apenas nos textos, entrevistas e intervenções em que sociólogo brasileiro dirige-se explicitamente ao nome Mariátegui, mas também nas anotações que fez na margem de diversos textos do pensador peruano, até então inéditas ao público, mostrando uma leitura rigorosa e atenta. Pois uma de suas contribuições originais foi adotar uma análise marxista descolonizadora da América Latina fora dos eixos da epistemologia europeia em um campo intelectual estreito. Talvez, dessa perspectiva, possa resultar a permanência definitiva, também no cenário brasileiro, da obra de JCM no rol das grandes interpretações marxistas da América Latina que priorizaram conhecer, explicar e transformar o tempo presente. 


\section{Deni Alfaro Rubbo}

é doutorando em Sociologia na Universidade de São Paulo (USP); bolsista Capes.

\section{Bibliografia}

ALIMONDA, H. 1983. José Carlos Mariátegui: redescobrir a América. São Paulo: Brasiliense.

ANDERSON, K. B. 2015. Marx aux antipodes: nations, ethnicité et sociétés non occidentales. Paris: Syllepse.

ARRUDA, M. A. N. 1995. Sociologia no Brasil: Florestan e a Escola

Paulista de Sociologia. In: MICELI, S. (org.). História das ciências sociais no Brasil. São Paulo: Sumaré.

. 1996. Arremate de uma reflexão: a revolução burguesa no Brasil

de Florestan Fernandes. Revista USP, São Paulo, n. 29, pp. 56-65.

BELLOTO, M. L.; CORRÊA, A. M. M. (orgs.). 1982. José Carlos Mariátegui. São Paulo: Ática.

BENJAMIN, W. 2007. Passagens. Belo Horizonte/São Paulo: Ed. UFMG/

Imprensa Oficial do Estado de São Paulo.

BIANCHI, A. 2010. O marxismo fora do lugar. Política E Sociedade, Florianópolis, n. 9, pp. 177-204.

BRAGA, R.; GARCIA, S. G.; SILVA, L. M. 2009. Sociologia pública: considerações a partir do Brasil. In: BRAGA, R.; BURAWOY, M. Por uma sociologia pública. São Paulo: Alameda.

CANDIDO, A. 1996. Lembrando Florestan Fernandes. São Paulo: s. ed.

CERQUEIRA, L. 2004. Florestan Fernandes: vida e obra. São Paulo: Expressão Popular.

COHN, G. 1987. O ecletismo bem temperado. In: D’INCAO, M. A. (org.). O saber militante: ensaios sobre Florestan Fernandes. São Paulo: Paz e Terra/ Ed. Unesp.

COSTA, D. V. A. 2010. Florestan Fernandes e a América Latina. Boletín

Onteariken, n. 10, pp. 48-62.

FERNANDES, F. 1975. Prefácio. In: MARIÁTEGUI, J. C. Sete ensaios de interpretação da realidade peruana. São Paulo: Alfa Ômega.

. 1976. "Em busca de uma sociologia crítica e militante". In:

A sociologia no Brasil. Petrópolis: Vozes.

. 1978. A condição de sociólogo. São Paulo: Hucitec.

1981. Reflexões sobre as "revoluções interrompidas" (uma rotação

de perspectivas). In: . Poder e contrapoder na América Latina. Rio

de Janeiro: Zahar. 
1994. Significado actual de José Carlos Mariátegui. Anuario Mariateguiano, Lima, Amauta, n. 6, pp. 81-87.

1995. "Em defesa do socialismo". In: Em busca do socialismo: últimos escritos $\mathcal{E}$ outros textos. São Paulo: Xamã. . 2005 [1975]. A revolução burguesa no Brasil. São Paulo: Globo. 2015 [1995]. A contestação necessária: retratos intelectuais de inconformistas e revolucionários. São Paulo: Expressão Popular.

FERNANDES, H. 1998. Amor aos livros - reminiscências de meu pai em sua biblioteca. In: VV. AA. Florestan ou o sentido das coisas. São Paulo: Boitempo. FERNÁNDEZ, O. 2010. Itinerario y trayectos heréticos de José Carlos Mariátegui. Santiago: Quimantú.

FORGUES, R. 1993. Mariátegui, lazo de unión entre América y Europa.

In: VV. AA. Encuentro Internacional José Carlos Mariátegui y Europa: el outro aspecto del descubrimiento. Lima: Amauta.

GARCIA, S. G. 2002. Destino impar. São Paulo: Editora 34.

ILLAN, D. M. 1974. José Carlos Mariátegui y su pensamiento revolucionário. Lima: IEP.

LOSADA, A. 1977. Os sistemas literários como instituições sociais na América Latina. Contexto, São Paulo, Hucitec, n. 2.

LÖWY, M. 1999. Pontos de referência para uma história do marxismo na América Latina. In: LÖWY, M. (org). O marxismo na América Latina: uma antologia de 1909 aos dias atuais. São Paulo: Fundação Perseu Abramo.

LUNA VEGAS, R. 1985. Historia y trascendencia de las cartas de Mariátegui. Lima: s. ed.

MARIÁTEGUI, J. C. 1969 [1928]. 7 ensayos de interpretación de la realidad peruana. Lima: Amauta. 1975 [1928]. Sete ensaios de interpretação da realidade peruana. São Paulo: Alfa Ômega. . 1988a [1929]. El problema de las razas en la América Latina. In: Ideología y política. Lima: Amauta. .1988b [1929]. Punto de vista antiimperialista. In: Ideología y política. Lima: Amauta. 2010. Sete ensaios de interpretação da realidade peruana. São Paulo: Expressão Popular/CLASCO.

MARTINS, J. S. 1998. Florestan: sociologia e consciência social no Brasil. São Paulo: Edusp.

MAZZEO, M. 2013. El socialismo enraizado: José Carlos Mariátegui: vigencia de su concepto de "socialismo práctico". Lima: FCE.

MELIS, A. 1994. José Carlos Mariátegui hacia el siglo XXI. In: MARIÁTEGUI, J. C. Mariátegui Total. Lima: Amauta. Tomo I. 
1999. Mariátegui, primer marxista de America. In:

Leyendo

Mariátegui. Lima: Amauta.

MOTA, C. G. 1998. Florestan: memória e utopia. In: VV. AA. Florestan ou o sentido das coisas. São Paulo: Boitempo.

NETTO, J. P. 1987. A recuperação marxista da categoria de revolução. In:

D'INCAO, M. A. (org.). O saber militante: ensaios sobre Florestan Fernandes. São Paulo: Paz e Terra/Ed. Unesp.

PARIS, R. 1981. La formación ideológica de José Carlos Mariátegui. México:

Pasado y Presente.

PERICÁS, L. B. 2010. José Carlos Mariátegui e o Brasil. Estudos Avançados,

São Paulo, n. 24, v. 68, pp. 335-61.

2011. Mariátegui, os Sete ensaios, a APRA e a Internacional

Comunista. In: ALIAGA, L.; AMORIM, H.; MARCELINO, P. (orgs.).

Marxismo: teoria, história e política. São Paulo: Alameda.

QUIJANO, A. 1980. Introducción a Mariátegui. Lima: Mosca Azul.

REYES, C. A. 1996. Mariátegui y el colonialismo. Notas sobre la revuelta literária de 1916. Anuario Mariateguiano, Lima, Amauta, n. 8, pp. 26670.

RICUPERO, B. 2008. Florestan Fernandes. In: Sete lições sobre as

interpretações do Brasil. São Paulo: Alameda.

RODRIGUES, L. S. 2010. Florestan Fernandes: interlúdio. São Paulo: Hucitec.

ROUILLON, G. 1963. Bio-bibliografía de José Carlos Mariátegui. Lima:

Universidad Nacional Mayor de San Marcos. 1975. La creación heroica de José Carlos Mariátegui. Lima: Arica.

Tomos I e II.

SCORSIM, L. 2006. Mariátegui: vida e obra. São Paulo: Expressão Popular.

SEREZA, H. C. 2005. Florestan: a inteligência militante. São Paulo: Boitempo. TIBLE, J. 2013. Marx selvagem. São Paulo: Annablume.

VÁSQUEZ, A. S. 1998. Mariátegui, grandeza e originalidade de um marxista latino-americano. In: PERICÁS, L. B.; BARSOTTI, P. (orgs.).

América Latina: história, ideias e revoluções. São Paulo: Xamã.

VV. AA. 1998. Florestan ou o sentido das coisas. São Paulo: Boitempo.

\section{Entrevistas concedidas ao autor}

ANA Maria Martinez Corrêa, setembro de 2014.

DIOGO Valença de Azevedo Costa, setembro de 2014. 


\section{“NOSSO IRMÃO MAIS VELHO": FLORESTAN FERNANDES, LEITOR DE MARIÁTEGUI}

\section{DENI ALFARO RUBBO}

Resumo: Florestan Fernandes é um dos pioneiros na divulgação da obra de José Carlos Mariátegui no Brasil. O objetivo central deste artigo é analisar e interpretar algumas manifestações do encontro entre Florestan e Mariátegui. Em primeiro lugar, levantaremos algumas das principais ocorrências da obra do pensador peruano nos textos, entrevistas e intervenções públicas do sociólogo brasileiro. Em segundo lugar, disponibilizaremos o resultado de uma pesquisa no arquivo Fundo Florestan Fernandes, que lança luz sobre o trabalho materializado ao longo das leituras feitas por Florestan: são inúmeros grifos, anotações, questionamentos inscritos nos livros do pensador peruano que o sociólogo tinha disponíveis em sua biblioteca particular. Assim, procuraremos reforçar a ideia de que muitos dos problemas levantados pelo Amauta no Peru na década de 1920 e, por extensão, na América Latina, suscitaram realmente o interesse daquele que é considerado o maior sociólogo brasileiro.

Palavras-chave: Florestan Fernandes; José Carlos Mariátegui; América Latina; Marxismo.

\section{“OUR OLDER BROTHER": FLORESTAN FERNANDES, A READER OF MARIÁTEGUI}

Abstract: Florestan Fernandes is one of the pioneers in disseminating the work of José Carlos Mariátegui in Brazil. The central aim of this article is to analyze and interpret some manifestations of Fernandes's encounter with Mariátegui. First, we will present some of the main instances of the Peruvian thinker's work in the texts, interviews, and public addresses made by the Brazilian sociologist. Second, we will provide the results of a research made at the Fundo 
Florestan Fernandes archive, which sheds some light on the work being done during the course of Fernandes's readings: countless marks, notes, and questions written in the margins of books by the Peruvian thinker that the sociologist had access to in his personal library. Thus, we seek to reinforce the idea that many of the problems raised by Amauta regarding Peru during the 1920s - and, by extension, Latin America - truly aroused the interest of Fernandes, who is considered Brazil's greatest sociologist.

Keywords: Florestan Fernandes; José Carlos Mariátegui; Latin America; Marxism.

Recebido: 08/09/2015 Aprovado: 07/10/2016 